\title{
Evaluation of knowledge, attitude and practices of postgraduate medical students towards clinical research in a tertiary care teaching hospital
}

\author{
Sukhmeen Kaur Johar ${ }^{1 *}$, Deepali L. Jaybhaye ${ }^{1}$, Shruti Chandra1 ${ }^{1}$, Prashant S. Mishra ${ }^{2}$
}

\author{
${ }^{1}$ Department of Pharmacology, MGM Medical College, Aurangabad, Maharashtra, India \\ ${ }^{2}$ Department of Pharmacology, Dr. VMGMC College, Aurangabad, Maharashtra, India
}

Received: 04 May 2021

Accepted: 29 May 2021

\section{*Correspondence:}

Dr. Sukhmeen Kaur Johar,

Email: sukhmeensk13@gmail.com

Copyright: (C) the author(s), publisher and licensee Medip Academy. This is an open-access article distributed under the terms of the Creative Commons Attribution Non-Commercial License, which permits unrestricted non-commercial use, distribution, and reproduction in any medium, provided the original work is properly cited.

\begin{abstract}
Background: Clinical research is a component of medical and health research that facilitates valuable knowledge regarding diagnosis, prevention as well as treatment of a disease. Nowadays, the practise of medicine is evidence-based and combining medical education with clinical research provides a channel for translating scientifically advanced knowledge into better public health. The aim of the study was to assess knowledge (K), attitude (A), and practices (P) about clinical research among post graduate medical students.

Methods: After obtaining institutional ethics committee approval, a cross-sectional and questionnaire-based study was conducted. A pre-structured and validated KAP questionnaire comprising of 25 questions (knowledge-15, attitude-5 and practices-5) was shared online through google forms with post graduate students. The responses to the questions were later marked correct or incorrect. The data was collected and compiled using Microsoft excel and expressed in percentage (\%). Data analysis was performed using SPSS version 25.0.

Results: 102 students responded to the questionnaire completely. Out of which males (55.9\%) pre-dominated and majority of the PG students belonged to I year accounting for $40.2 \%$. About $61.76 \%$ PG students were aware about a clinical research unit in the college. Majority of the students acknowledged the necessity of conducting clinical research and exhibited good knowledge about key concepts of clinical trials. Even responses to questions pertaining to attitude towards clinical research were also majorly positive. On the contrary, more than $90 \%$ students had neither attended any workshop on ICH-GCP guidelines nor registered their academic study under clinical trial registry of India. However, $73.5 \%$ of them expressed their willingness to participate in a clinical trial in future.

Conclusions: Although, assessment of knowledge and attitudes about clinical research among post graduate students showed positive results but discrepancies were observed in its practise. As such, this necessitates incorporation of clinical research activities into existing medical education system.
\end{abstract}

Keywords: Clinical research, Knowledge, Attitude, Practices, Questionnaire, Post graduate students

\section{INTRODUCTION}

Clinical research is a component of medical and health research that helps to determine safety and efficacy of medications, therapeutic regimes, devices and diagnostic products meant for human use. As such, it facilitates valuable knowledge regarding diagnosis, prevention as well as treatment of a disease. ${ }^{1,2}$ Indian clinical trial industry has experienced an expeditious growth in the recent years. ${ }^{3}$ Economic globalization, outsourcing of clinical trials to India by numerous multinational companies and availability of suitable infrastructure contributes to this flourishing industry in India. ${ }^{3}$ Moreover, our country has English as primary and medical language which provides an additional benefit for the conduct of clinical trials. ${ }^{4}$ 
Nowadays, the practise of medicine is evidence-based and combining medical education with clinical research provides a channel for translating scientifically advanced knowledge into better public health. ${ }^{5}$ However, it has been observed that research programs in medical colleges are not prioritised due to insufficient funds and manpower resources which finally leads to degradation of research oriented medical education. ${ }^{6}$ Although undergraduate medical students are taught briefly about drug discovery and drug development process (phases of clinical trial) in pharmacology curriculum but it lacks practical exposure. On the other hand, postgraduate (PG) students are mandated to undertake a dissertation project as a part of their MD/MS curriculum through which they get exposed to the concept of design and conduct of research. ${ }^{7}$ However, as compared to pharmacology PG students, the level of awareness regarding basic concepts of clinical research is quite adequate among other medical students. ${ }^{5}$ In a study by Deo MG, it was observed that among $1,00,000$ Indian medical students, only $0.9 \%$ exhibited keen interest in research. ${ }^{8}$ In conduct of clinical research, investigators, who are generally experts in the condition being studied, have numerous responsibilities. They should make sure that a clinical trial is conducted in an ethical manner and complies to regulatory requirements as well as International conference on Harmonisation Good Clinical practise (ICH-GCP) guidelines. ${ }^{9}$ But many studies in the past suggest that our country produces highly skilled clinicians but lacks skilled investigators. ${ }^{10}$

Numerous clinical trials are being conducted in various departments of MGM Medical college and Hospital, Aurangabad. PG students assist clinical trial investigators in documentation and subject related activities. As the situation of clinical research is improving in India, today's medical students might become investigators in clinical trials or pursue career in clinical research in future. The aim of the study was to assess the three quotientsknowledge $(\mathrm{K})$, attitude $(\mathrm{A})$, and practices $(\mathrm{P})$ about clinical research among PG students.

\section{METHODS}

A cross-sectional and questionnaire-based study was conducted in MGM Medical college and Hospital, Aurangabad from 20 Janaury 2020 to 20 February 2020. The study commenced following approval from institutional Ethics committee (MGM-ECRHS). An online structured questionnaire with an annexed informed consent form was developed using Google forms and the link for the same was shared through WhatsApp. Only those who gave consent could access the questionnaire. All the PG students from various clinical and non-clinical departments in MGM Medical college, Aurangabad were included in the study. The participation was voluntary. Incompletely filled questionnaires were excluded from the study. The questionnaire was divided into two sections with several questions pertaining to: (1) sociodemographic details; and (2) KAP towards clinical research. The socio-demographic details included age, gender, department and year of residency. The KAP consisted of 15 questions relevant to knowledge regarding clinical research, 5 questions probed attitude towards clinical research and 5 questions were related to practices towards clinical research. These questions were designed based upon earlier studies for assessing KAP about clinical research. ${ }^{5,7,11-13}$ Finally, the designed questionnaire was analysed and validated by experts involved in clinical research. All these questions were either multiple choice or dichotomous (yes/no; agree/ disagree). The responses for the same were later marked as correct or incorrect. The data was collected and compiled using Microsoft excel and expressed by using percentage. Data analysis was performed using SPSS version 25.0.

\section{RESULTS}

During the study, 104 PG students from various clinical and non-clinical departments responded to the questionnaire. Two questionnaires were incompletely filled; hence they were excluded from the study. The demographic details of all the participants are represented in Table 1. Out of 102 participants, 57 (55.9\%) were males and $45(44.1 \%)$ were females. Majority of the PG students belonged to I year accounting for $40.2 \%$, followed by III year $(32.35 \%)$ and II year $(27.45 \%)$. Also, respondents from department of medicine predominated.

Table 1: Demographic profile of postgraduate students.

\begin{tabular}{|ll|}
\hline Variables & Values \\
\hline Age $($ mean \pm SD) $($ years $)$ & $25.86 \pm 1.463$ \\
\hline Gender & \\
\hline Male & $57(55.9)$ \\
\hline Female & $45(44.1)$ \\
\hline Year of residency & \\
\hline I year & $41(40.2)$ \\
\hline II year & $28(27.45)$ \\
\hline III year & $33(32.35)$ \\
\hline
\end{tabular}

Table 2: Department wise distribution of participants.

\begin{tabular}{|ll|}
\hline Department & Number of students \\
\hline Anaesthesia & 9 \\
\hline Dermatology & 6 \\
\hline ENT & 1 \\
\hline General surgery & 14 \\
\hline Medicine & 16 \\
\hline OBGY & 9 \\
\hline Ophthalmology & 7 \\
\hline Orthopaedics & 7 \\
\hline Paediatrics & 8 \\
\hline Pathology & 4 \\
\hline Pharmacology & 2 \\
\hline Psychiatry & 5 \\
\hline Radiology & 9 \\
\hline Respiratory medicine & 5 \\
\hline Total & 102 \\
\hline
\end{tabular}


Responses of PG students to questions related to knowledge of clinical research are summarised in Table 3. As far as awareness of a clinical research unit in MGM Medical College, Aurangabad is concerned, $61.76 \%$ PG students were aware about it (K1). Also, 85.3\% students acknowledged the necessity of conducting clinical research by medical professionals (K2). Moreover, majority of the PG students exhibited good knowledge about role of regulatory body i.e., DCGI in India (K3), importance of Informed consent form (K4), phases of clinical trial (K6, K7), ICH- GCP guidelines (K8, K9, $\mathrm{K} 12$ ) and some important concepts related to clinical trials such as randomization (K10), placebo (K11), reimbursement for clinical trial participation and Adverse drug reaction (ADR) reporting (K15). However, positive response to question regarding importance of Assent form in paediatric population was given by only $36.27 \%$ students (K5). Similarly, very few students (35.3\%) responded correctly regarding the term 'non-inferiority trial' (K13).

Table 3: Knowledge of postgraduate students about clinical research.

\begin{tabular}{|c|c|c|c|}
\hline Sr. No. & Questions & $\begin{array}{l}\text { Correct } \\
\text { response- } \mathbf{N}\end{array}$ & $\begin{array}{l}\text { Incorrect } \\
\text { response- } \mathbf{N}\end{array}$ \\
\hline K1 & $\begin{array}{l}\text { Is there a clinical research unit in MGM medical college, Aurangabad? } \\
\text { Yes*/No }\end{array}$ & 63 (61.76) & $39(38.24)$ \\
\hline K2 & $\begin{array}{l}\text { Do you consider it is necessary for medical professionals to conduct clinical } \\
\text { research? } \\
\text { Yes*/No }\end{array}$ & $87(85.3)$ & 15 (14.7) \\
\hline K3 & $\begin{array}{l}\text { From whom to seek approval for conducting clinical research using new drugs } \\
\text { in India? } \\
\text { a. DCGI* } \\
\text { b. ICMR } \\
\text { c. DTAB } \\
\text { d. Both a and b }\end{array}$ & $86(84.3)$ & $16(15.7)$ \\
\hline K4 & $\begin{array}{l}\text { Which document is mandatory to enrol a subject in a clinical research study? } \\
\text { a. Study protocol } \\
\text { b. Case record form } \\
\text { c. Informed consent form* } \\
\text { d. Investigator's brochure }\end{array}$ & 73 (71.57) & $29(28.43)$ \\
\hline K5 & $\begin{array}{l}\text { When doing research in paediatric population, which of the following need(s) } \\
\text { to be obtained? } \\
\text { a. Informed consent from parent or guardian } \\
\text { b. Informed consent from the child } \\
\text { c. Assent from the child of } 7 \text { years and above } \\
\text { d. Both a and c* }\end{array}$ & $37(36.27)$ & $65(63.73)$ \\
\hline K6 & $\begin{array}{l}\text { Phase I clinical trial is done in } \\
\text { a. Healthy volunteers } \\
\text { b. Patients with malignancy or HIV } \\
\text { c. Both a and } b^{*} \\
\text { d. None }\end{array}$ & $77(75.5)$ & $25(24.5)$ \\
\hline K7 & $\begin{array}{l}\text { In which phase of a clinical trial is post-marketing surveillance done? } \\
\text { a. I } \\
\text { b. II } \\
\text { c. III } \\
\text { d. IV* }\end{array}$ & $55(53.9)$ & $47(46.1)$ \\
\hline K8 & $\begin{array}{l}\text { What is ICH-GCP? } \\
\text { a. International conference on Harmonisation- Good Clinical Practise* } \\
\text { b. International council on Harmonisation- Good Clinical Practise } \\
\text { c. Intermittent conference of Harmonisation- Good Clinical Practise } \\
\text { d. Either a or b }\end{array}$ & $89(87.25)$ & $13(12.75)$ \\
\hline K9 & $\begin{array}{l}\text { A subject's participation in a clinical trial is } \\
\text { a. Voluntary and may withdraw consent at any time* } \\
\text { b. Voluntary but may not withdraw consent } \\
\text { c. Mandatory } \\
\text { d. Both a and b }\end{array}$ & $98(96.1)$ & $4(3.9)$ \\
\hline K10 & $\begin{array}{l}\text { In a clinical trial, when allocation of subjects to treatment groups is by chance, } \\
\text { it is known as } \\
\text { a. Allocation concealment }\end{array}$ & $79(77.45)$ & $23(22.55)$ \\
\hline
\end{tabular}




\begin{tabular}{|c|c|c|c|}
\hline Sr. No. & Questions & $\begin{array}{l}\text { Correct } \\
\text { response- N }\end{array}$ & $\begin{array}{l}\text { Incorrect } \\
\text { response- } \mathbf{N}\end{array}$ \\
\hline & $\begin{array}{l}\text { b. Randomization* } \\
\text { c. Blinding } \\
\text { d. None }\end{array}$ & & \\
\hline K11 & $\begin{array}{l}\text { Which of the following is true regarding placebo? } \\
\text { a. It is a pharmaceutically inert substance } \\
\text { b. It is also known as the sugar pill. } \\
\text { c. It is unethical to use a placebo for the control arm in a clinical trial when a } \\
\text { standard treatment already exists. } \\
\text { d. All of the above* }\end{array}$ & $100(98.04)$ & $2(1.96)$ \\
\hline K12 & $\begin{array}{l}\text { ICH-GCP guidelines are followed in all of the following except } \\
\text { a. Phase I trial } \\
\text { b. Pre-clinical trial* } \\
\text { c. Phase IV trial } \\
\text { d. Phase II trial }\end{array}$ & $80(78.43)$ & $22(21.57)$ \\
\hline K13 & $\begin{array}{l}\text { Which would be the most suitable form of trial, if the test product is as } \\
\text { effective as the comparator but may be a little better? } \\
\text { a. Non-inferiority trial* } \\
\text { b. Superiority trail } \\
\text { c. Equivalence trial } \\
\text { d. Either a or b }\end{array}$ & $36(35.3)$ & $66(64.7)$ \\
\hline K14 & $\begin{array}{l}\text { Clinical trial subjects should be reimbursed for trial participation in all the } \\
\text { following cases except } \\
\text { a. Time spent in coming to trial site and loss of daily wages due to trial } \\
\text { participation } \\
\text { b. Travel cost incurred in coming to the site } \\
\text { c. Payment offered to encourage trial participation* } \\
\text { d. Both a and b }\end{array}$ & $81(79.4)$ & $21(20.6)$ \\
\hline K15 & $\begin{array}{l}\text { Which of the following should be reported by investigator when an adverse } \\
\text { event occurs in a clinical trial? } \\
\text { a. Institutional Ethics committee } \\
\text { b. Regulatory Authority } \\
\text { c. Sponsor } \\
\text { d. All of the above* }\end{array}$ & $88(86.3)$ & $14(13.7)$ \\
\hline
\end{tabular}

Table 4: Attitude of postgraduate students about clinical research.

\begin{tabular}{|c|c|c|c|}
\hline Sr. No. & Questions & Agree & Disagree \\
\hline A1 & $\begin{array}{l}\text { Do you think the potential benefit of clinical research is to deliver basic need } \\
\text { for betterment of mankind and health status? }\end{array}$ & 68 (66.67) & $34(33.34)$ \\
\hline A2 & $\begin{array}{l}\text { Do you think by participation in clinical trials, doctors obtain a better } \\
\text { understanding of the disease and contributes to medical progress? }\end{array}$ & $80(78.43)$ & $22(21.57)$ \\
\hline A3 & $\begin{array}{l}\text { Do you think conducting clinical trials is just a waste of time, manpower and } \\
\text { money? }\end{array}$ & 17 (16.67) & $85(83.34)$ \\
\hline A4 & $\begin{array}{l}\text { Do you think undertaking clinical research increases burden on already } \\
\text { overworked post graduate students? }\end{array}$ & $91(89.2)$ & $11(10.8)$ \\
\hline A5 & $\begin{array}{l}\text { Do you think training in ICH-GCP guidelines should be incorporated in PG } \\
\text { curriculum? }\end{array}$ & $67(65.7)$ & $35(34.3)$ \\
\hline
\end{tabular}

Figures in parentheses indicate percentage

Table 5: Practices of postgraduate students about clinical research.

\begin{tabular}{|llll|}
\hline Sr. No. & Questions & Yes & No \\
\hline P1 & Have you anytime read any article related to clinical research? & $72(70.6)$ & $30(29.4)$ \\
\hline P2 & Have you ever participated in a clinical trial? & $4(3.9)$ & $98(96.1)$ \\
\hline P3 & Have you attended a workshop on ICH-GCP guidelines? & $10(9.8)$ & $92(90.2)$ \\
\hline P4 & Have you registered your academic study under clinical trial registry of India? & $2(1.96)$ & $100(98.04)$ \\
\hline P5 & Are you willing to participate in a clinical trial in future? & $75(73.5)$ & $27(26.5)$ \\
\hline
\end{tabular}

Figures in parentheses indicate percentage 
As shown in Table 4, 68\%, 80\% and 67\% PG students agreed that clinical research delivers basic need for the betterment of mankind and health status (A1), participation in clinical trials ensures better understanding of disease and contributes to medical progress (A2) and training in ICH-GCP guidelines should be incorporated in PG curriculum respectively (A3). Also, 83.34\% responders disagreed with the statement that conducting clinical trials is just a waste of time, manpower and money (A4). On the contrary, 91\% students supported that undertaking clinical research increases burden on already overworked PG students (A4).

As depicted in Table 5, majority of the students (72\%) had read any article related to clinical research $(\mathrm{P} 1)$ but only $3.9 \%$ had a chance to participate in any clinical trial in the past (P2). Moreover, more than 90\% students had neither attended any workshop on ICH-GCP guidelines (P3) nor registered their academic study under clinical trial registry of India (P4). However, $73.5 \%$ students expressed their willingness to participate in a clinical trial in future (P5)

\section{DISCUSSION}

In the last few decades, India has emerged as a muchpreferred clinical trials hub by global pharmaceutical companies. $^{4,14}$ Although review of clinical research activities in our country advocates the presence of highly skilled physicians but it cannot assure the presence of skilled investigators. ${ }^{10,15}$ For effective conduction of clinical trials, there is a dire necessity of proficient and highly trained personnel who are well-versed with ICHGCP guidelines. Therefore, proper training in clinical research will definitely ensure integrity of clinical trial conducted in India. ${ }^{16}$

The present study was a questionnaire-based study conducted in post graduate students of a tertiary care teaching hospital with the aim to assess their knowledge, attitude and practices about clinical research. In this study, it was observed that the overall knowledge about the needs and pre-requisites of clinical research was fairly good among the post graduate students. In contrast, in studies by Kanna et al, Sharma et al and Vittalrao et al; the overall awareness about clinical trials was found to be less. ${ }^{5,17,18}$ Also, in our study, very few students had an opportunity to participate in clinical trials in the past which complies with a study conducted by Sabzwari et al. ${ }^{19}$

Discrepancy between attitude and practices was also observed in this study. Although, majority of the students considered clinical research as an unnecessary burden on already overworked PG students but still most of them wished to get involved in clinical research in future. Their current inhibitions to involve in clinical research can be attributed to time constraints during residency and inadequate guidance from teaching staff. Similar obstacles to research practices were observed in a study by Pawar et al. ${ }^{7}$
Also, in this study, the number of participants who obtained formal education in ICH-GCP guidelines through workshop was very low. Our findings are consistent with a study by Dhodi et al which also showed inadequate knowledge of GCP guidelines among investigators. ${ }^{20}$

\section{CONCLUSION}

We concluded in this study, that that the post graduate students had a relatively good knowledge and attitude but lack in practices towards clinical research. Majority of them acknowledged the importance of clinical trials but only a few had participated in them. Lack of formal training in ICH-GCP guidelines and under sensitization of PG students regarding clinical research is mainly responsible for this. The findings of our study advocates importance of educational interventions, mandatory course in ICH-GCP guidelines and continuous guidance by mentors to increase involvement of PG students in clinical trials. As such, this study provides insight into planning of future programmes that can encourage our clinicians to undertake clinical research in the upcoming years.

\section{Limitations}

Since, our study sample was drawn based on convenience sampling technique which included 102 post graduate students that responded to the questionnaire. Thus, its results regarding knowledge, attitude and practices about clinical research may not be generalizable to all post graduate students. Moreover, this was a single centre study which further limits the generalizable of results.

Funding: No funding sources

Conflict of interest: None declared

Ethical approval: The study was approved by the Institutional Ethics Committee

\section{REFERENCES}

1. Institute of Medicine (US) Clinical Research Roundtable. In: Tunis S, Korn A, Ommaya A, eds. The Role of Purchasers and Payers in the Clinical Research Enterprise: Workshop Summary. Washington: National Academies Press; 2002.

2. Zodpey SP, Negandhi HN. Training in clinical research in India: potential and challenges. Indian $\mathbf{J}$ Community Med. 2009;34(3):173-4.

3. Vennu V, Dahiya S. Awareness and Opinions of Research Professionals on India's New Drug and Clinical Trials Regulations: Protocol for a CrossSectional Web-Based Survey Study. JMIR Res Protoc. 2020;9(1):14744.

4. Selvarajan S, George M, Kumar SS, Dkhar SA. Clinical trials in India: Where do we stand globally? Perspect Clin Res. 2013;4(3):160-4.

5. Kanna RS, Alla J, Krishnakanth K. Knowledge of medical students on clinical trials. Int $\mathrm{J}$ Basic Clin Pharmacol. 2019;8:1484-8. 
6. Entrance exams- Education and career in India. Requirement for Research Oriented Medical Education in India, 2020. Available at: http://entranceexam.net/requirement-for-research-oriented-medicaleducation-in-india/. Accessed on 24 April 2021.

7. Pawar DB, Gawde SR, Marathe PA. Awareness about medical research among resident doctors in a tertiary care hospital: A cross-sectional survey. Perspect Clin Res. 2012;3(2):57-61.

8. Deo MG. Undergraduate medical students' research in India. J Postgrad Med. 2008;54(3):176-9.

9. Baer AR, Devine S, Beardmore CD, Catalano R. Clinical investigator responsibilities. J Oncol Pract. 2011;7(2):124-8.

10. Burt T, Sharma P, Dhillon S, Manchanda M, Mittal S, Trehan N. Clinical Research Environment in India: Challenges and Proposed Solutions. J Clin Res Bioeth. 2014;5(6):1-8.

11. Sumi E, Murayama T, Yokode M. A survey of attitudes toward clinical research among physicians at Kyoto University Hospital. BMC Med Educ. 2009;9:75.

12. Deodurg PM, Bagewadi HG, Patil BV, Dass AP. Knowledge, attitude and practices towards medical research among resident doctors at a tertiary care Hospital. Indian J Pharma Pharmacol. 2017;4(3):1259.

13. Pardeshi A, Pardeshi P. Knowledge, Attitude \& Practices of Clinical Research with Special Reference to GCP (Good Clinical Practice) among Post-graduate Medical Students \& Medical Teachers in a Tertiary Care Hospital, Pune- A Cross-sectional Survey. IJSRM. 2016;4(3):231-43.

14. Clinuity. India emerging as hub for clinical trials says ASSOCHAM, 2011. Available at: http://www.clinuity.com/blog/2011/07/indiaemerging -as-hub-for-clinical-trials-says-assocham. Accessed on 24th April 2021.
15. Ali R, Finlayson A, Indox Cancer Research Network. Building capacity for clinical research in developing countries: the INDOX Cancer Research Network experience. Glob Health Action. 2012;5.

16. Goel D, Walia R, Sharma P, Kaur H, Agnihotri P. Impact of educational intervention on knowledge, attitude and awareness of good clinical practice among health care providers. Perspect Clin Res. 2017;8(2):90-4.

17. Sharma KH, Jindal A. Low awareness of clinical research in India amongst final year medical students and physicians: Need for increased emphasis on clinical research in medical curriculum. Arch Med Health Sci. 2014;2(2):234

18. Vittalrao MA, Kumari MK, Bhatt SV, Gill R, Thomson SR. A Questionnaire Survey on awareness of Clinical Trials Among Medical Students. Biomed Pharmacol J. 2018;11(4):2005-9.

19. Sabzwari S, Kauser S, Khuwaja AK. Experiences, attitudes and barriers towards research amongst junior faculty of Pakistani medical universities. BMC Med Educ. 2009;9:68.

20. Dhodi DK, Thakkar KB, Billa G, Khobragade AA, Sinha SR, Patel SB. Knowledge, attitude and practices of medical students and teachers towards clinical research in a Tertiary Care Hospital in Mumbai, a Cross sectional survey. J Contemp Med Educ. 2013;1:238-44.

Cite this article as: Johar SK, Jaybhaye DL, Chandra S, Mishra PS. Evaluation of knowledge, attitude and practices of postgraduate medical students towards clinical research in a tertiary care teaching hospital. Int J Basic Clin Pharmacol 2021;10:800-5. 